\title{
Simulation of Snow Drift and the Effects of Snow Particles on Wind
}

\author{
Jie Zhang and Ning Huang \\ Key Laboratory of Mechanics on Western Disaster and Environment, The Ministry of Education of China, \\ Department of Mechanics, Lanzhou University, Lanzhou 730000, Gansu, China \\ Correspondence should be addressed to Ning Huang, huangn@lzu.edu.cn
}

Received 14 June 2008; Accepted 18 December 2008

Recommended by Andrzej Dzielinski

Coupled equations between wind and saltating particles are presented for a stable wind blowing over an infinite plane bed and the equations are solved for a simplified particle-bed impact process. The calculated results show that the saltating snow particles strongly affect the velocity distribution of the wind, causing a deviation from a logarithmically distributed wind velocity profile. The average height and length of saltating snow particle trajectories exponentially increase as the friction velocity increases; the ejected snow number flux and the streamwise snow transport rate also increase as the friction velocity increases.

Copyright (c) 2008 J. Zhang and N. Huang. This is an open access article distributed under the Creative Commons Attribution License, which permits unrestricted use, distribution, and reproduction in any medium, provided the original work is properly cited.

\section{Introduction}

Blowing snow occurs in many parts of the world and can originate from a variety of sources, including ice cover, mountain glaciers, and avalanches [1]. It also contributes to natural disasters such as ice-snow floods, avalanches, and mudslides [2] that negatively impact local environments and economies and sometimes cause the loss of human life.

In China, blowing snow is common throughout the provinces of Qinghai, Tibet, Gansu, Sichuan, and Inner Mongolia. Snow frequently accumulates on highways in these regions, causing considerable traffic delays, and the diminished visibility due to blowing snow results in hazardous driving conditions [3].

Wind-snow interactions have been studied as far back as the early twentieth century, when the characteristics of blowing snow were investigated in Antarctica [4]. Later, many other studies examined the movement and trajectory of snow particles via wind tunnel experiments, high-speed photography, and theoretical and numerical analyses (e.g., [5-8]). In China, extensive wind tunnel simulations of windsnow interactions have been conducted with the aim of developing a qualitative approach to minimize the destructive effects of blowing snow [3].

Several recent theoretical analyses of saltating snow particles (such as [2, 9-11]) do not address how such particles affect the wind velocity distribution, thus their conclusions may have limited practical use, given that saltating particles have long been known to appreciably change the speed of the wind that drives them $[6,7]$. This paper will present coupled equations between wind and saltating particles for a stable wind blowing over an infinite plane bed, and the equations will be solved for a simplified particle-bed impact process.

\section{Force Analysis of a Snow Particle in Wind}

High-speed photographs of snow particles in a wind tunnel [12] revealed several distinct types of motion that arise at different wind speeds. As wind speed becomes progressively higher, the following types of particle motion appear: vibrating in place, rolling along the snow surface, slipping along the snow surface, saltating (bouncing) along the snow surface, and suspension in air while moving along with the wind. When saltation is present, it is the predominant mode of particle movement [12] and so it is our main concern.

Surface grains with a dendritic shape tend to be broken by impacting grains, thus grains become small and more elastic in time and the bulk density increases [13], so people usually assumed the drifting snow grains to be spherical in their research [14-16]). Figure 1 depicts the forces (not to scale) exerted on a spherical snow particle in a region, where 


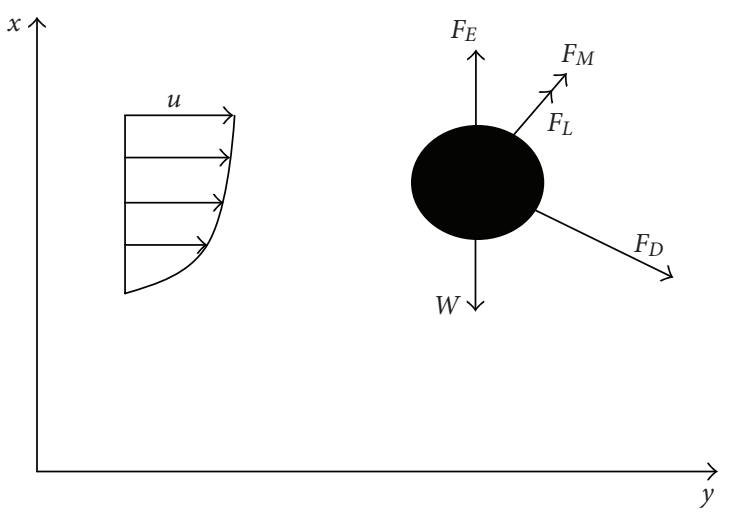

FIGURE 1: Forces acting on a saltating particle.

wind flows in the positive $x$ direction and where $y$ is the particle height above the bed. $D_{P}$ and $\rho_{P}$ are the snow particle diameter and density, respectively.

$\rho$ and $g$ are the air density and gravitational acceleration, respectively; and forces acting on the particle are (1) weight $W ;(2)$ aerodynamic drag $F_{D} ;(3)$ aerodynamic lift $F_{L} ;(4)$ Magnus lift (due to particle spin) $F_{M}$; (5) electrical force $F_{E}$.

The weight may be expressed as

$$
W=\frac{1}{6} \pi D_{P}^{3}\left(\rho_{P}-\rho\right) g .
$$

The wind speed, $u$, is greater than the speed of the saltating particle with respect to the snow surface, so the drag force on the particle acts in the positive $x$ direction and can be expressed as $[17,18]$

$$
F_{D}=\frac{1}{8} C_{D} \rho \pi D_{P}^{2} V_{r}^{2}
$$

where $C_{D}$ is the drag coefficient and $V_{r}$ is the velocity of the particle relative to the air. $V_{r}$ is given by

$$
V_{r}=\left[\left(\frac{d x}{d t}-u\right)^{2}+\left(\frac{d y}{d t}\right)^{2}\right]^{1 / 2} .
$$

For a spherical particle, the drag coefficient is given by the empirical formula [19]

$$
C_{D}=\frac{24}{\operatorname{Re}}+\frac{6}{1+(\operatorname{Re})^{1 / 2}}+0.4,
$$

where Re is the Reynolds number, which may be expressed as

$$
\operatorname{Re}=\frac{D_{p}}{\nu} V_{r}
$$

where $v$ is the kinematic viscosity of air.

Experiments have shown that the forces $F_{L}, F_{M}$, and $F_{E}$ are typically two orders of magnitude smaller than $W$ and $F_{D}[17]$, so we will not consider them.

\section{Equations of Motion and Boundary Conditions}

To analyze the saltation of snow particles, we must consider (1) the acceleration of the particles by the wind, (2) the force on the wind due to saltating particles, (3) the collision of particles with the snow surface. For a stable wind blowing over an infinite plane bed, Ungar and Haff [17], Werner [20], and so on applied a modified Navier-Stokes equation:

$$
F_{x}+\frac{d}{d y}\left(\rho k^{2} y^{2}\left(\frac{d u}{d y}\right)^{2}\right)=0,
$$

where $F_{x}$ is the horizontal force per unit volume on the wind due to the presence of saltating particles, $k$ is von Karman's constant, $y$ is the height above the snow surface, and $u$ is the wind speed in the $\mathrm{X}$-direction.

The two dominant forces acting on a snow particle can be decomposed into $x$ and $y$ components to yield the equations of motion for its two-dimensional trajectory:

$$
\begin{aligned}
& m_{p} \frac{d^{2} x}{d t^{2}}=f_{x}=-\frac{1}{2} C_{D} \rho V_{r}\left(\frac{d x}{d t}-u\right) \pi\left(\frac{D_{p}}{2}\right)^{2}, \\
& m_{p} \frac{d^{2} y}{d t^{2}}=f_{y}=-m g-\frac{1}{2} C_{D} \rho V_{r}\left(\frac{d y}{d t}\right) \pi\left(\frac{D_{p}}{2}\right)^{2},
\end{aligned}
$$

where $x$ and $y$ are the horizontal and vertical coordinates, respectively, $g$ is the acceleration due to gravity, $m_{p}$ and $D_{p}$ are the snow particle mass and diameter, and $f_{x}, f_{y}$ are the $x$ and $y$ components of the net force experienced by the particle.

During the process of saltation, each particle will cross the same height $y$ twice, once upward and once downward. Let $\sigma_{\uparrow(y)}$ and $\sigma_{\downarrow(y)}$ be equal to the number density of upward and downward particles, respectively, as a function of height. Similarly, let $f_{x \uparrow}$ and $f_{x \downarrow}$ be equal to the horizontal force on a single upward and downward particle. By Newton's third law, per unit volume, the horizontal force exerted on the wind must be equal and opposite to the horizontal force exerted on the particles:

$$
F_{x}=-\left[\sigma_{\uparrow(y)} f_{x \uparrow}+\sigma_{\downarrow}(y) f_{x \downarrow}\right] .
$$

This equation can be rewritten as

$$
F_{x}=-s\left[\frac{f_{x \uparrow}}{\dot{y}_{\uparrow(y)}}-\frac{f_{x \downarrow}}{\dot{y}_{\downarrow}(y)}\right],
$$

where $s$ is the number of particles ejected per unit area of bed per unit time (assuming all particles are ejected at the same initial speed), $\dot{y}_{\uparrow(y)}$ and $\dot{y}_{\downarrow}(y)$ are the vertical speed of a single upward and downward particle, respectively.

When a saltating grain approaches the snow bed with a velocity $V_{i}$, the number of ejected grains with is given by [17]

$$
S\left(\vec{V}_{0}, \vec{V}_{i}\right)=A \frac{V_{i}^{2}}{D_{p} g} \delta^{3}\left(\vec{V}_{0}-B \frac{V_{i}^{3}}{D_{p} g} \vec{e}_{y}\right),
$$

where $V_{i}$ is the magnitude of $\vec{V}_{i}, \vec{e}_{y}$ is the unit vector in the positive y direction, $\vec{V}_{0}$ is the lift-off velocity of a vertically ejected grain, $A$ and $B$ are dimensionless constants. Obviously, (10) means that a saltating grain impacts the bed with a speed $\vec{V}_{i}$, then the number of ejected grains with a same speed $B V_{i}^{3} /\left(D_{p} g\right) \vec{e}_{y}$ is $A V_{i}^{2} /\left(D_{p} g\right)$. 


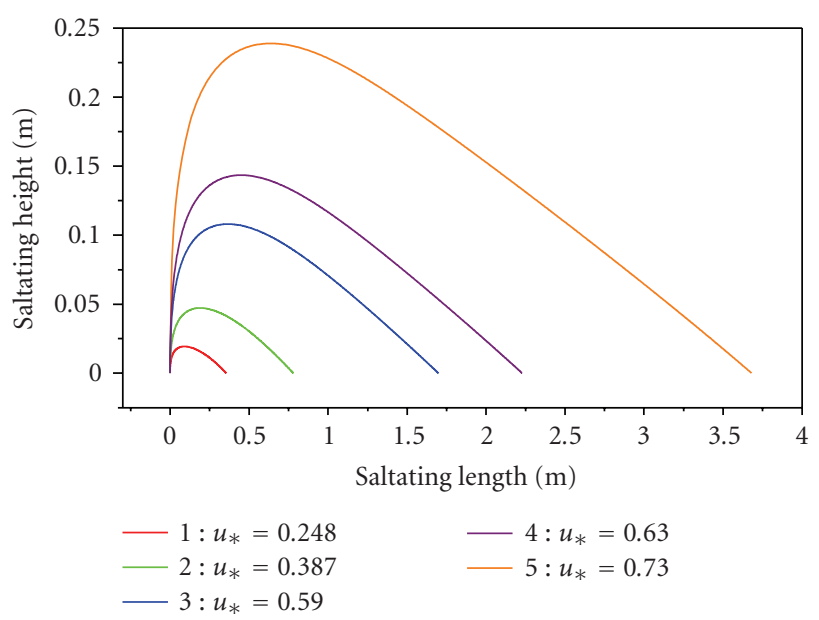

(a)

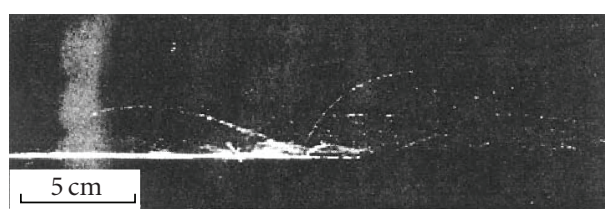

(i)

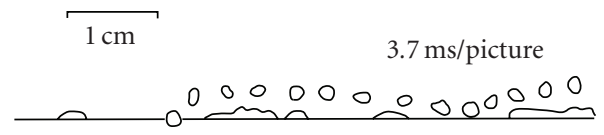

(ii)

(b)

FIgURE 2: (a) Saltation trajectories at different friction velocities. (b) (i) Photograph of particle trajectories. (ii) Trace of particle motion on the internal of each spot is $3.7 \mathrm{~m} / \mathrm{s}$.

For (6), the effective bed roughness is $D_{p} / 30$, giving us the boundary condition $y=D_{p} / 30, u=0$.

Assuming all grains are ejected at the same speed, (7) are solved using the boundary condition

$$
u_{*}=\lim \left(k y \frac{d u}{d y}\right) .
$$

\section{Computational Method}

According to Bagnold [21], the transport of grains is limited, for a given wind speed, by an "equilibrium mechanism" whereby the number of grains per unit time ejected into the saltation layer is equal to that falling onto the bed. Thus, for each grain that impacts the bed, another grain enters the saltation layer. So in (10), the value of $A V_{i}^{2} /\left(D_{p} g\right)$ is unity.

Based on observations at air temperatures less than $-6^{\circ} \mathrm{C}$, Zhonglong and Yuan [1] classified surface snow particles into three types: new snow (diameter less than $1.0 \mathrm{~mm}$, average density $0.06 \mathrm{~g} / \mathrm{cm}$ ), fine snow (diameter less than $0.5 \mathrm{~mm}$, average density less than $0.18 \mathrm{~g} / \mathrm{cm}$ ), and old fine snow (diameter from $0.5 \mathrm{~mm}$ to $1.0 \mathrm{~mm}$, average density

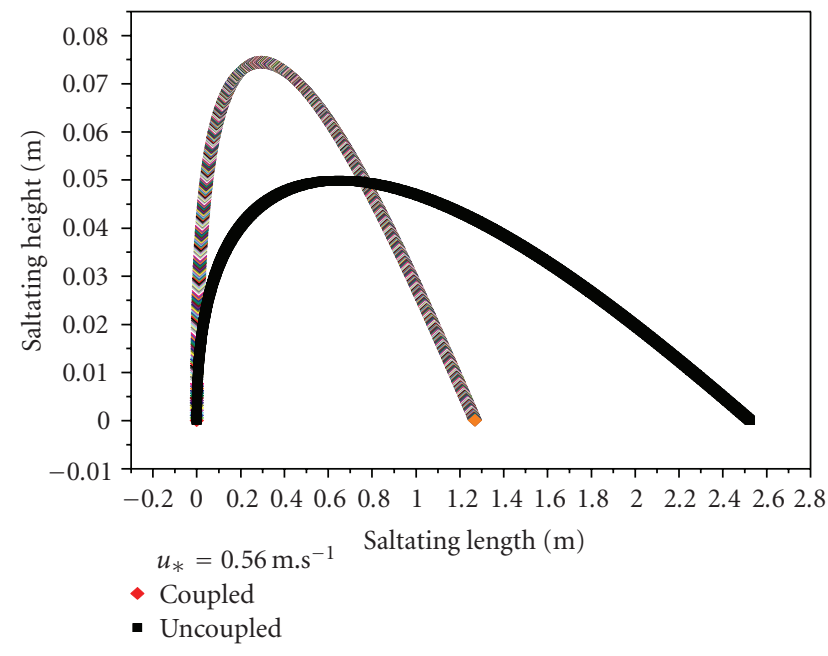

(a)

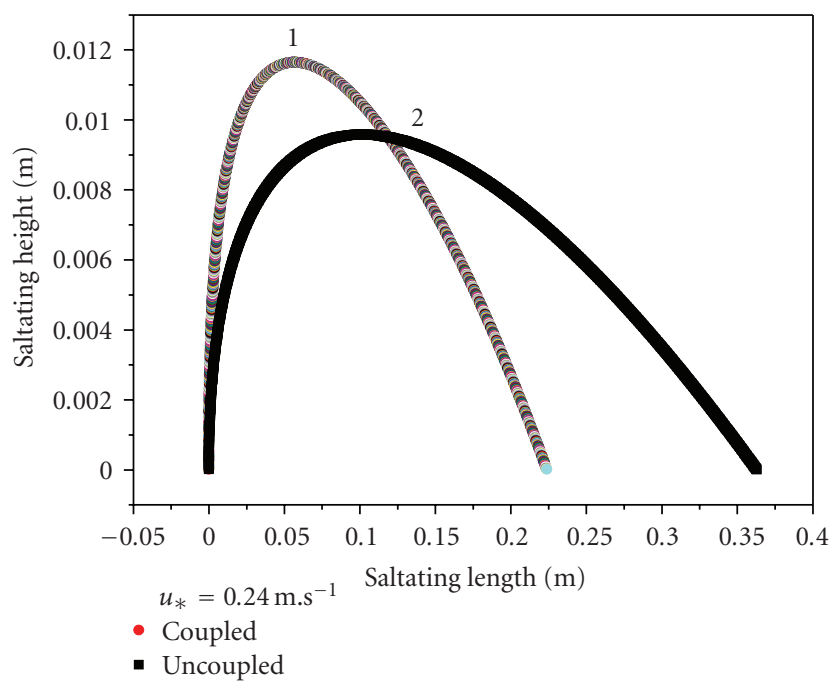

(b)

FIGURE 3: (a) A comparison of coupled and uncoupled particle trajectories for $u_{*}=0.56 \mathrm{~m} / \mathrm{s}$. (b) A comparison of coupled and uncoupled particle trajectories for $u_{*}=0.24 \mathrm{~m} / \mathrm{s}$.

$0.23 \mathrm{~g} / \mathrm{cm}$ ). The experimental results with which we compare our theoretical results are limited to fine snow.

Zhonglong [3] identified a threshold wind speed for fine snow particles, at a height of $1.85 \mathrm{~m}$, of $3.65 \mathrm{~m} / \mathrm{s}$; below this speed, the number of saltating grains is too small to cause a measurable decrease in wind speed. From this result, the particle lift-off speed $V_{0}$ can be calculated and then used to solve (7) to find $V_{i}$. Then, by solving (6) and (7), we can obtain the wind profile and the snow particle trajectory.

To reach a numerical solution,

(1) input values for $s$ and for $d u / d y$ at $y=D_{p} / 30$ and then solve (6),

(2) substitute the result from (6) into (7) to calculate the particle trajectory and find the value of $V_{i}$, 


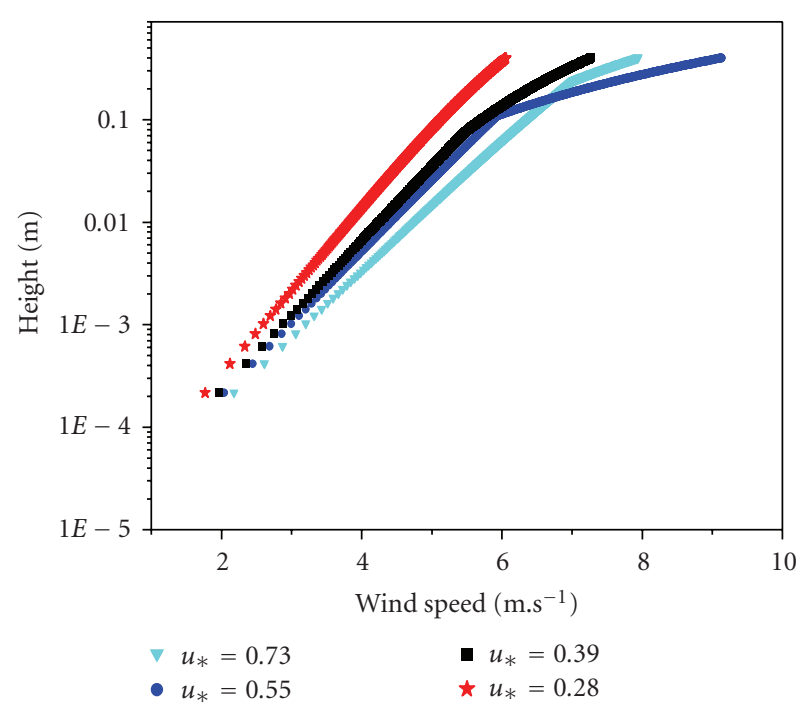

FIgURE 4: Calculated wind profiles with drifting fine snow.

(3) substitute the results from (7) into (9) to calculate $F_{x}(y)$ and then substitute $F_{x}(y)$ into (6),

(4) repeat the process 1-3 until the wind profile calculated in step (3) adequately approaches the value calculated in step (1),

(5) if the precision condition $\left|V_{i}-\sqrt{D_{p} g / A}\right|<\varepsilon$ ( $\varepsilon$ is a positive number with a sufficient small value) is not satisfied, then the input values must be adjusted accordingly, and (6), (7), and (9) solved iteratively until the condition is satisfied.

\section{Analysis of Results}

For snow-wind coupling, the particle trajectory heights and lengths will increase with the friction velocity (Figure 2(a)).

Figures 3(a) and 3(b) compare the coupled and uncoupled particle trajectories at two different friction velocities.

The particle trajectory is strongly influenced by coupling. When $u_{*}=0.56 \mathrm{~m} / \mathrm{s}$, the coupled trajectory height exceeds the uncoupled height by $48 \%$; when $u_{*}=0.24 \mathrm{~m} / \mathrm{s}$, the coupled trajectory height exceeds the uncoupled height by $20 \%$.

Kikuchi [6], Maeno et al. [7], and Zhonglong [3] observed that snow-wind coupling causes the vertical wind velocity profile to deviate from a logarithmic distribution. In Figure 4, our calculated results illustrate this deviation at different friction velocities; the effect tends to be more pronounced at higher wind speeds when the ejected particle rate $s$ is greater.

Figures 5(a) and 5(b) show our calculated results for coupled and uncoupled wind profiles based on the experimental data of Zhonglong [3]. Our coupled profile is qualitatively consistent with Wang's result.

Figure 6 compares our calculations of trajectory height versus friction velocity with Wang's experimental result (grain diameter $=0.5 \mathrm{~mm}$, mean density $=0.9 \mathrm{~g} / \mathrm{cm}^{3}$ ).

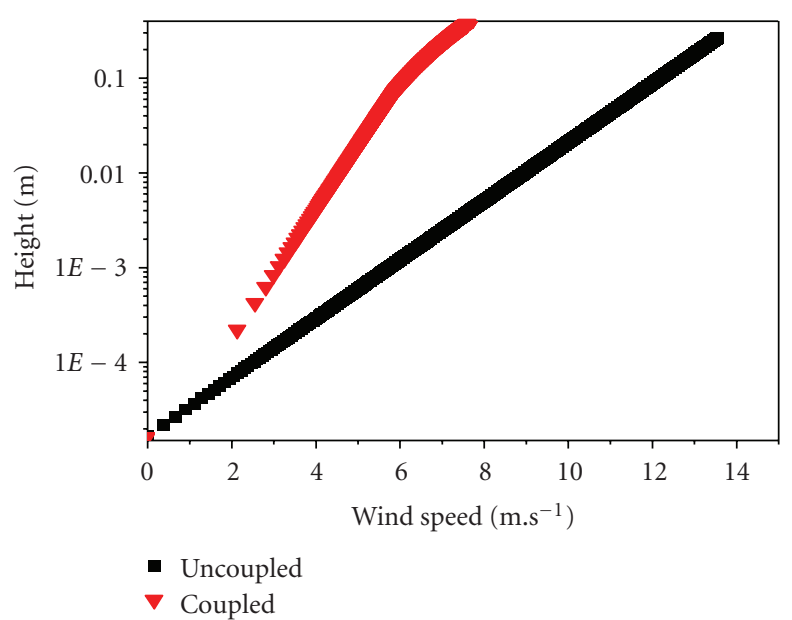

(a)

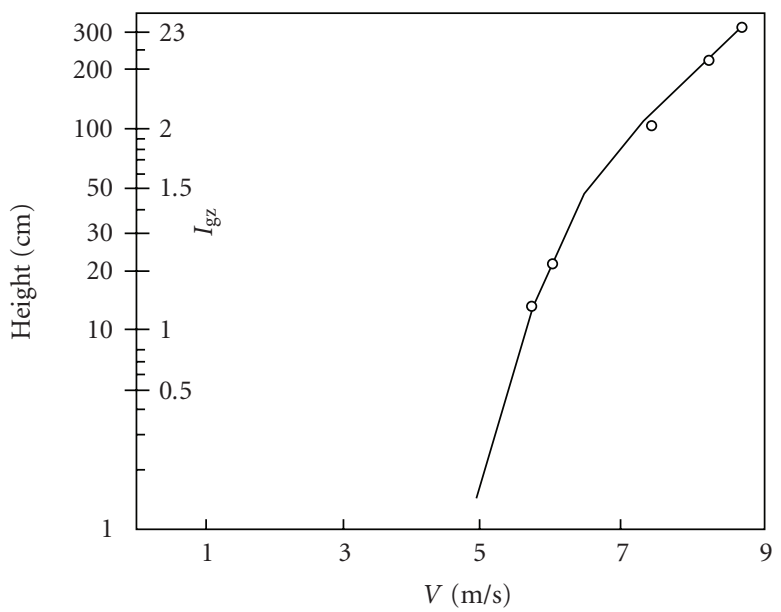

(b)

Figure 5: (a) A comparison of the coupled and uncoupled wind velocity profiles. (b) The experimentally determined wind profile of Zhonglong [3].

According to Zhonglong [3], the average height of saltating snow particles increases exponentially with friction velocity. Figure 6 shows a numerical fit of our calculated values, which is given by

$$
H=\alpha_{1} \exp \left(\frac{u_{*}}{\beta_{1}}\right)+\lambda_{1},
$$

where

$$
\alpha_{1}=0.00527 \mathrm{~m}, \quad \beta_{1}=0.19 \mathrm{~m} / \mathrm{s}, \quad \lambda_{1}=-0.0032 \mathrm{~m} .
$$

Figures 7(a) and 7(b) compare our calculated values of particle trajectory length versus friction velocity with the experimental result of Maeno et al. [8], showing qualitative agreement. A numerical fit for our values is given by

$$
L=\alpha_{2} \exp \left(\frac{u_{*}}{\beta_{2}}\right)+\lambda_{2},
$$




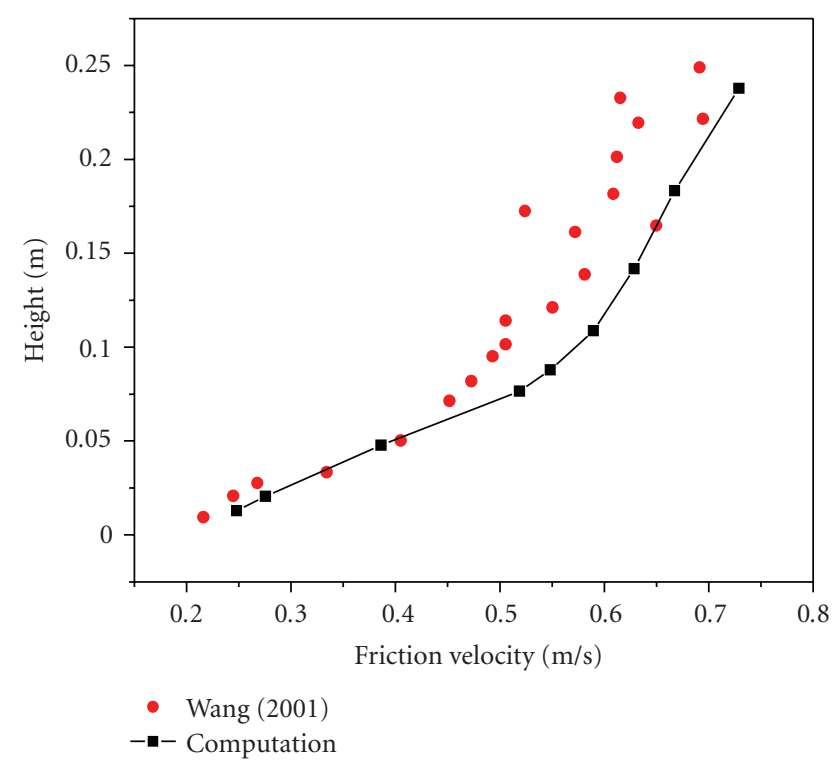

FiguRE 6: Trajectory height versus friction velocity.

where

$$
\alpha_{2}=0.083 \mathrm{~m}, \quad \beta_{2}=0.19 \mathrm{~m} / \mathrm{s}, \quad \lambda_{2}=0.00052 \mathrm{~m} \text {. }
$$

We have used our numerical model to calculate $s$, the number of ejected particles per unit area of bed per unit time, based on the experimental results of Zhonglong [3]. Figure 8 shows these values as a function of friction velocity, an exponential relationship that is given by

$$
N=\alpha_{3} \exp \left(\frac{u_{*}}{\beta}\right)+\lambda_{3},
$$

where $\alpha_{3}=4127.1 \mathrm{~m}^{-2} \mathrm{~s}^{-1}, \beta_{3}=0.15 \mathrm{~m} / \mathrm{s}$, and $\lambda_{3}=$ $-16541.4 \mathrm{~m}^{-2} \mathrm{~s}^{-1}$.

Zhonglong [3] proposed, based on experimental results, that the saltation transport rate varies as the cube of friction velocity. Figure 9 shows our calculated values for $Q$, the transport rate per unit width of bed, which is linear to the cube of friction velocity for $u_{*}^{3}$ greater than $0.2 \mathrm{~m}^{3} / \mathrm{s}^{3}$. Our result is consistent with that of Dziji [5], validating our theoretical model in this respect.

\section{Conclusion}

In this paper, coupled equations between wind and saltating snow particles are presented for a stable wind blowing over an infinite plane bed, and the equations are solved for a simplified particle-bed impact process.

(1) Snow-wind coupling results in considerably different particle trajectories when compared to a model in which no coupling exists.

(2) The average height and length of saltating snow particles increase exponentially with friction velocity.

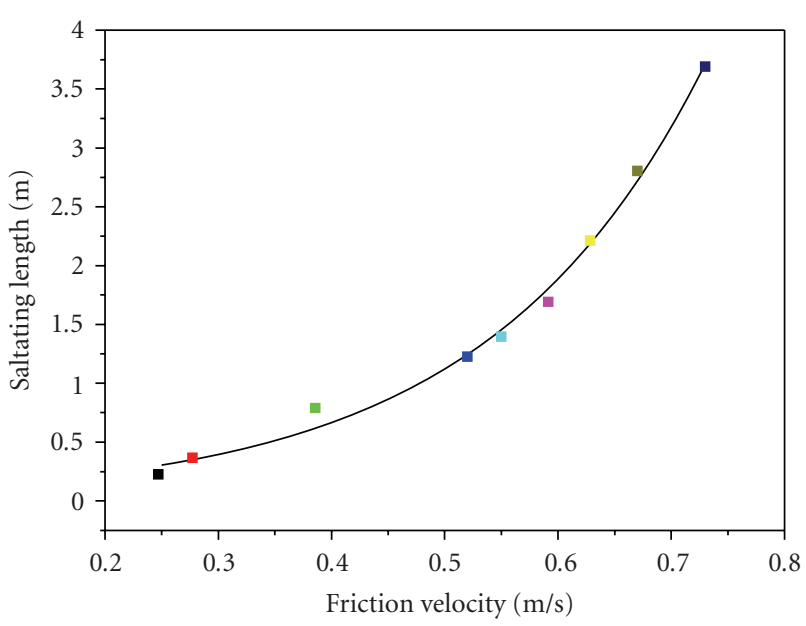

(a)

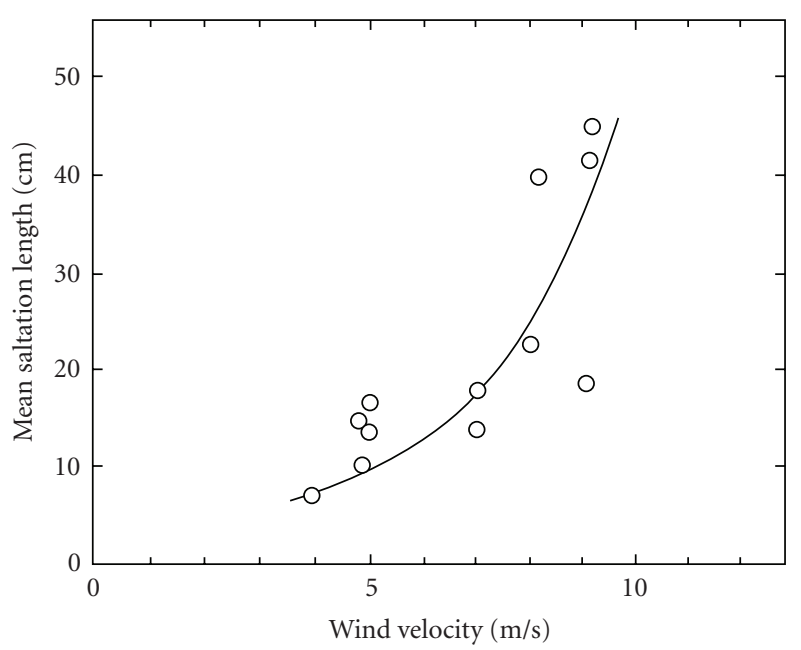

(b)

Figure 7: (a) Our results for trajectory length versus friction velocity. (b) The experimental result of Maeno et al. [8].

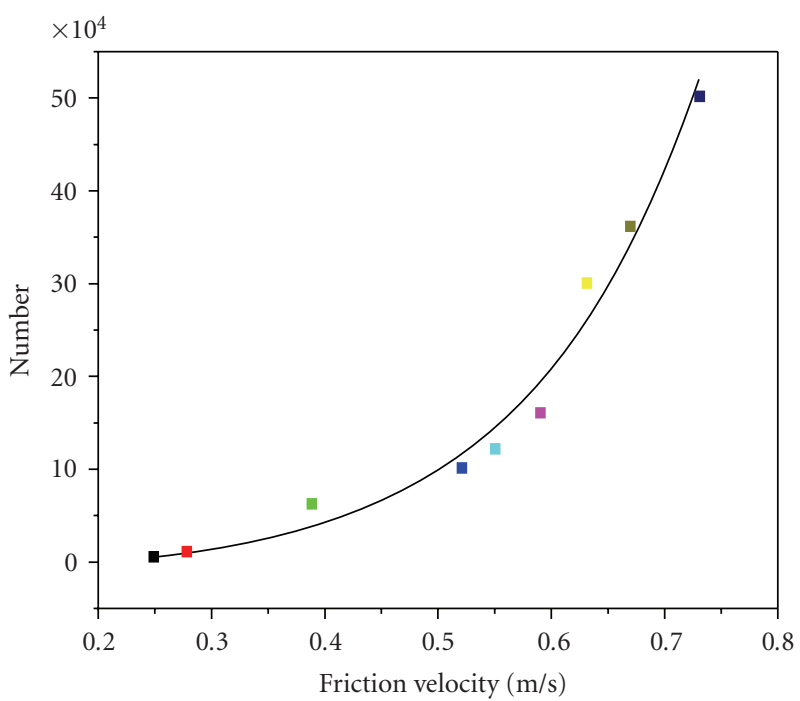

FIGURE 8: Ejected grain number versus friction velocity. 


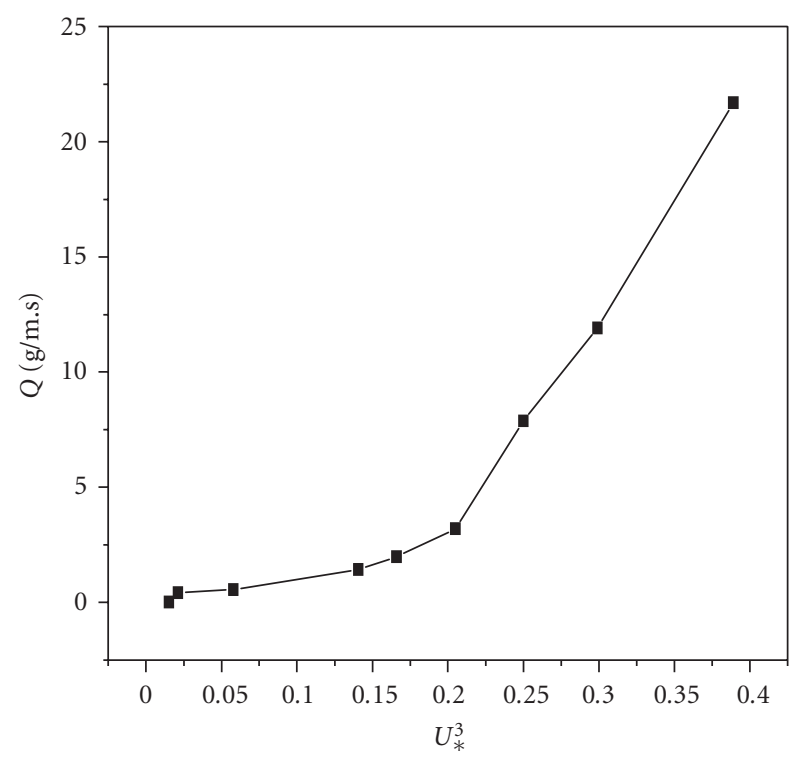

FIGURE 9: Saltation transport rate versus cube of friction velocity.

(3) Our model provides the number of particles ejected from a unit area of bed per unit time, given experimental data for particle trajectory height and friction velocity.

(4) The transport rate of saltating particles is linear to the cube of friction velocity, in agreement with Kobayashi [5].

\section{Acknowledgments}

This research was partially supported by a grant from the National Natural Science Foundation of China (10772073, 40571018), Joint Project of NSFC and ANR (10811130470), the New Century Outstanding Talent of the Ministry of Education of China, and the Science Fund of the Ministry of Education of China for Ph.D. Program.

\section{References}

[1] W. Zhonglong and C. Yuan, "Research on prevention of snowdrifts by blower fences," Journal of Glaciology, vol. 26, no. 94, pp. 435-445, 1980.

[2] J. L. Michaux, F. Naaim-Bouvet, K. Kosugi, A. Sato, and T. Sato, "Study in a climatic wind tunnel (Cryospheric Environment Simulator) of the influence of the type of grain of snow and of the flow on the formation of a snow-drif," $L a$ Houille Blanche-Revue Internationale de l'Eau, no. 6-7, pp. 79-83, 2002.

[3] W. Zhonglong, Research on Snow Drift and Its Hazard Control Engineering in China, Lanzhou University, Lanzhou, China, 2001.

[4] G. C. Simpson, British Antarctic Expedition, 1910-1913. Meteorology. Volume 1, Thacker, Spink, Calcutta, India, 1919.

[5] K. Dziji, "Studies of snow transport in low-level drifting snow," Low Temperature Science, vol. 12, no. 8, pp. 73-79, 1972.
[6] T. Kikuchi, "A wind tunnel study of the aerodynamic roughness associated with drifting snow," Cold Regions Science and Technology, vol. 5, no. 2, pp. 107-118, 1981.

[7] N. Maeno, K. Araoka, K. Nishimura, and Y. Kaneda, "Physical aspects of the wind-snow interaction in blowing snow," Journal of the Faculty of Science, Hokkaido University. Series 7 , vol. 6, no. 1, pp. 127-141, 1980.

[8] N. Maeno, R. Naruse, K. Nishimura, et al., "Wind-tunnel experiments on blowing snow," Annals of Glaciology, vol. 6, pp. 63-67, 1985.

[9] R. Bintanja, "Modification of the wind speed profile caused by snowdrift: results from observations," Quarterly Journal of the Royal Meteorological Society, vol. 127, no. 577, pp. 2417-2434, 2001.

[10] R. Bintanja, "Buoyancy effects induced by drifting snow particles," Annals of Glaciology, vol. 32, pp. 147-152, 2001.

[11] S. Alhajraf, "Computational fluid dynamic modeling of drifting particles at porous fences," Environmental Modelling \& Software, vol. 19, no. 2, pp. 163-170, 2004.

[12] W. Zhonglong and X. Weirong, Study on the Evaporation of Grassland in the East Part of Qilian Mountain, vol. 3 of Memories of Glaciology and Geocryology, Institute of CAS, Science Press, Beijing, China, 1982.

[13] J. J. J. Doorschot and M. Lehning, "Equilibrium saltation: mass fluxes, aerodynamic entrainment, and dependence on grain properties," Boundary-Layer Meteorology, vol. 104, no. 1, pp. 111-130, 2002.

[14] R. A. Schmidt, "Threshold wind-speeds and elastic impact in snow transport," Journal of Glaciology, vol. 26, no. 94, pp. 453$467,1980$.

[15] R. Bintanja, "Snowdrift suspension and atmospheric turbulence-part I: theoretical background and model description," Boundary-Layer Meteorology, vol. 95, no. 3, pp. 343-368, 2000.

[16] M. Nemoto and K. Nishimura, "Numerical simulation of snow saltation and suspension in a turbulent boundary layer," Journal of Geophysical Research D, vol. 109, no. 18, Article ID D18206, 14 pages, 2004.

[17] J. E. Ungar and P. K. Haff, "Steady state saltation in air," Sedimentology, vol. 34, no. 2, pp. 289-299, 1987.

[18] R. S. Anderson and P. K. Haff, "Wind modification and bed response during saltation of sand in air," Acta Mechanica, vol. 1, supplement, pp. 21-51, 1991.

[19] F. Write, Viscous Fluid Flow, Mcgraw-Hill, New York, NY, USA, 1974.

[20] B. T. Wener, "A steady-state modrl of wind-blown sand transport," Journal of Geology, vol. 98, pp. 1-17, 1990.

[21] R. A. Bagnold, Physics of Blown Sand and Desert Dunes, Mathuen, London, UK, 1941. 

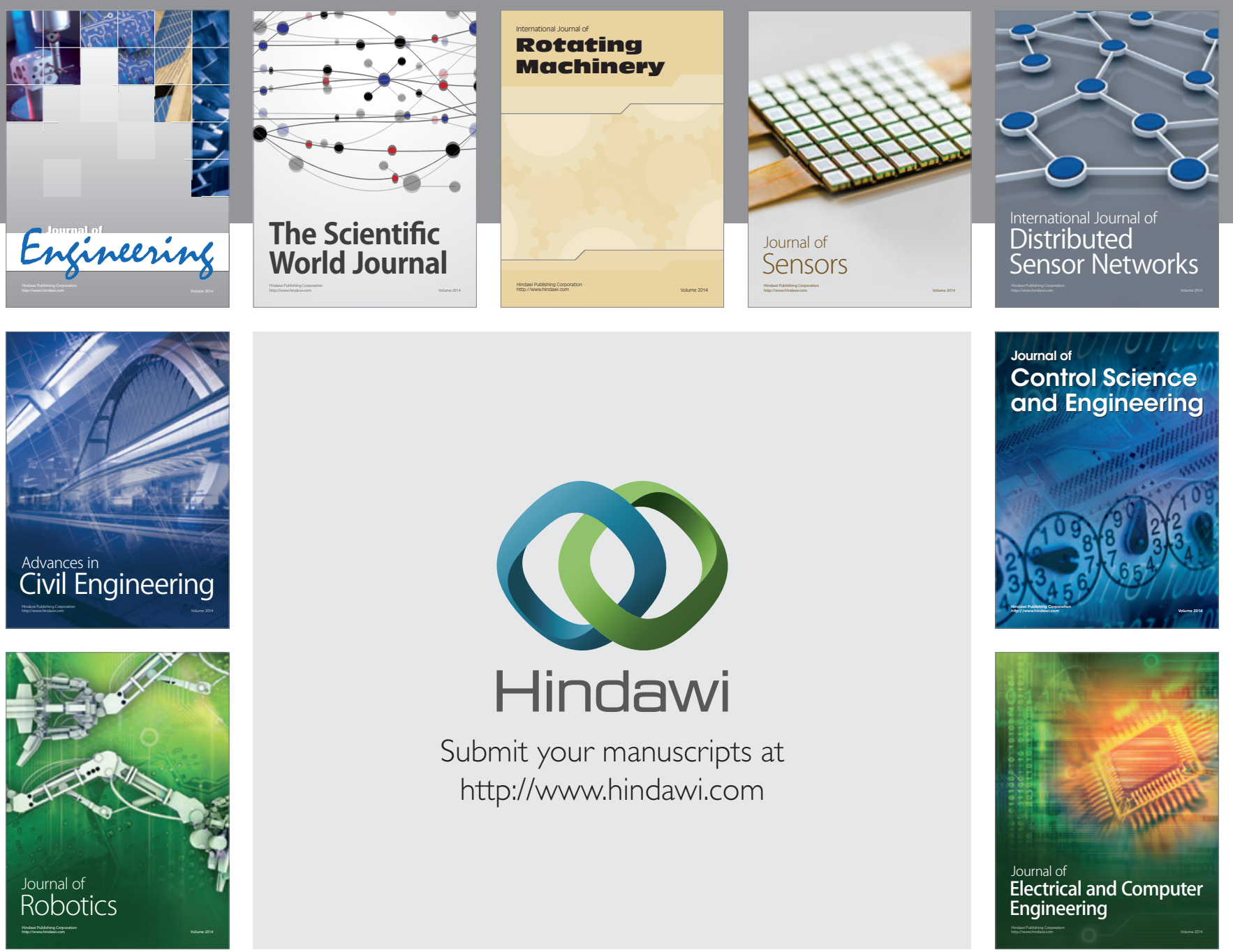

Submit your manuscripts at

http://www.hindawi.com
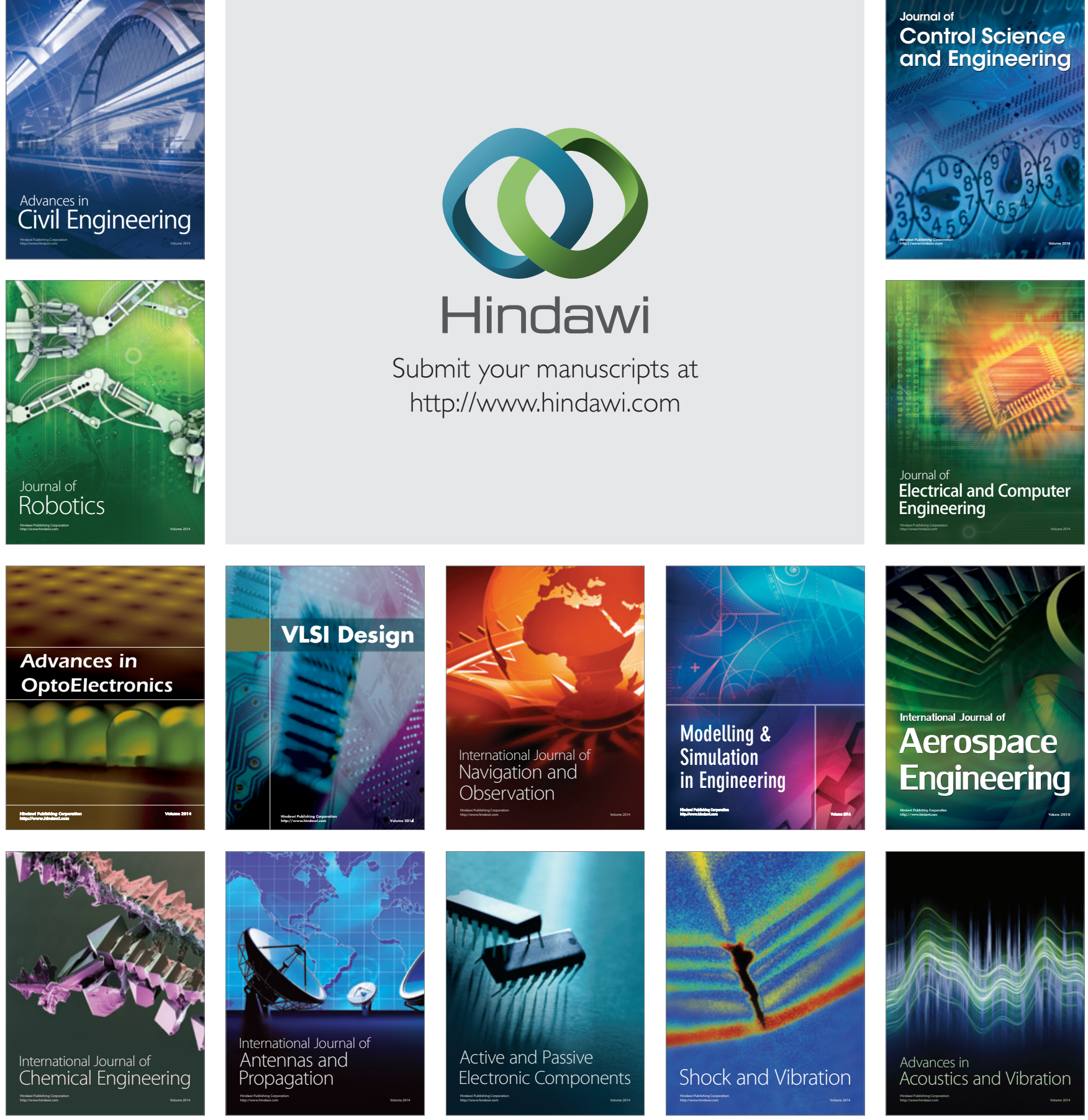